\title{
Perception of parents of children with and without disabilities about teething disturbances and practices adopted
}

\author{
Alessandra Maia de Castro Prado', Fabiana Sodré de Oliveira', Ludmilla de Melo Abrão², \\ Myrian Stella de Paiva Novaes' ${ }^{1}$, Thaís Thereza Basso Prado 2
}

${ }^{1}$ Pediatric Dentistry Area, Dental School, Federal University of Uberlândia, Uberlândia, MG, Brazil

${ }^{2}$ Dental School, Federal University of Uberlândia, Uberlândia, MG, Brazil

\begin{abstract}
Aim: To evaluate and compare the perception of parents of children with and without disabilities about the occurrence of local and systemic manifestations during the eruption of primary teeth and to investigate the parents' practices used to alleviate teething disturbances. Methods: A cross-sectional study was conducted in a sample of parents of children without disabilities (GI) and parents of children with disabilities (GII) treated at a University Pediatric Dentistry Clinic. Data from GI and GIl were collected using a structured questionnaire applied during an interview with the parents, and were analyzed using descriptive statistics. Mann-Whitney and Wilcoxon tests were employed and the level of significance was set at $p<0.05$. Results: The questionnaires were filled out by 86 parents, being 45 in $\mathrm{Gl}$ and 41 in Gll. For Gl, the most frequent local manifestations were edema around the tooth $(84.44 \%)$ and increased suction (75.56\%); and for Gll were edema and erythema around the tooth ( $78.05 \%$ and $70.73 \%$, respectively). The most frequent systemic manifestations, according to parents of both groups, were irritability and fever. There was no statistically significant difference between groups $(\mathrm{p}<0.05)$. It was observed that $46.66 \%$ and $68.3 \%$ of parents of $\mathrm{Gl}$ and $\mathrm{Gll}$, respectively, adopted different practices to alleviate teething disturbances. Conclusions: During primary teeth eruption, local and systemic manifestations may occur and different practices were adopted by the Interviewed parents, mainly those with children with disabilities.
\end{abstract}

Keywords: teething, primary teeth, eruption.

\section{Introduction}

Received for publication: December 21, 2012 Accepted: March 22, 2013

Correspondence to: Alessandra Maia de Castro Avenida Pará 1720, Bloco 2G, sala 02, CEP: 38405720

Campus Umuarama, Uberlândia, MG, Brasil Fone/fax: +553432182346 E-mail: odontoinfantil@yahoo.com.br fasoliv@yahoo.com.br
Parents and healthcare professionals consider dental eruption as a significant event in the growth and development of the child ${ }^{1}$.

Although it is a physiological process, the relationship between the process of the eruption and the onset of symptoms in child is controversial ${ }^{2-3}$. Some authors believe that there is a clear relationship between general or local disorders and eruption ${ }^{4-5}$, others consider the eruption a physiological process without any manifestation or correlation with any problem. A third group believes that eruption causes some discomfort in normal physiological process ${ }^{2}$.

A number of local and systemic manifestations have been associated with teething. The local manifestations most frequently cited are: red and sensitive gums, gingival edema, gum rubbing, a drooling rash in chin or face, flushed cheeks, pulling 
the ears, heavy drooling, mouth ulcers, cyst of eruption and digital sucking. The systemic manifestations included: fever, gastrointestinal perturbations (diarrhea, constipation, colic and vomiting), irritability, coughing due to excess of saliva, disturbed sleep, nasal discharge, loss of appetite and chewing objects ${ }^{6-8}$.

In a cohort study conducted in the Brazilian southern region, mothers of 500 infants reported that $73.0 \%$ of their children to suffer teething symptoms. The symptoms most frequently cited were irritability $(40.5 \%)$, fever $(38.9 \%)$, diarrhea $(36.0 \%)$ and itching $(33.6 \%)^{9}$.

Most studies were performed with healthy children, not with children with disabilities ${ }^{9-10}$. Thus, the objectives of this study were to evaluate and compare the perception of parents' of children with and without disabilities about the occurrence of local and systemic manifestations during the eruption of primary teeth and to investigate the parents' practices used to alleviate teething disturbances.

\section{Material and methods}

\section{Ethical Approval}

This study was approved by the Ethics Committee at the Federal University of Uberlândia (protocol number 085/ 05). Parents and/or guardians were invited to take part in the survey and a signed parental consent was obtained before beginning the study.

\section{Participants}

A convenience sample was recruited from parents of children (aged 8 months to 5 years) with primary teeth enrolled at a program of early attention to oral health at Dental School of the Federal University of Uberlandia, Brazil. The parents were separated in two groups: GI (parents of children without disabilities) and GII (parents of children with disabilities). Parents that did not agree to participate in the study and children aged older 5 years were excluded.

\section{Data collection}

The data collection was done through interview using a structured questionnaire with parents, which included the following questions: sociodemographic data about the child (age, gender and with or without disabilities); age that initiated the tooth eruption, a list of local and systemic manifestations that were observed during the tooth eruption, and one question about the practices that the parents adopted to manage these manifestations.

All interviews were conducted by a single researcher and the sequence of the questions was not changed. The terms were explained in a clear and understandable manner for parents and no limited number of answers was established for the topics about local and systemic manifestations.

The interviews were made in a waiting room of the Pediatric Dentistry Clinic during the appointments of the children. The parents of children with disabilities were interviewed at the Department of Special Needs Patients, a unit linked to the Dental Hospital (School of Dentistry -
Federal University of Uberlândia)

\section{Statistical Analysis}

Data was analyzed using descriptive statistics. Mann-Whitney and Wilcoxon tests were conducted to analyze data obtained for GI and GII. The level of significance was set at $\mathrm{p}<0.05$.

\section{Results}

In this study, 86 parents and/or guardians of children aged 8 months to 5 years old took part. In GI, 26 children were female and 19 were male (mean age $=2$ years and 5 months, with standard deviation $=9$ months); and in G II, 17 children were female and 24 male (mean age $=3$ years and 7 months, with standard deviation $=1$ year). This group included patients with cerebral palsy (68.28\%), Down syndrome (12.20), chronic systemic disease (12.20\%), neurological development delay (4.88\%) and endocrine metabolic disease $(2.44 \%)$.

In Tables 1 and 2 are demonstrated the results for the local and systemic manifestations observed by parents of each group. Edema around the tooth and irritability were the local and systemic manifestations, respectively, most observed by parents of both groups.

Tables 3 and 4 demonstrate the different behaviors adopted to manage local and systemic manifestations. It was not found statistically significant difference $(\mathrm{p}<0.05)$ between the groups. Parents of GI would rather to take child to a pediatric consultation $(20.0 \%)$, while the use of topical anesthetic was the measure adopted by $17.07 \%$ of parents of GII.

Table 1. Prevalence of local manifestations during dental eruption according to parents of GI and GII

\begin{tabular}{lll}
\hline Local Manifestations & GI (\%) & GII (\%) \\
Edema around the tooth & 84.44 & 78.05 \\
Increased suction & 75.56 & 41.46 \\
Increased salivation & 57.78 & 58.54 \\
Erythema around the tooth & 46.67 & 70.73 \\
Transient gingival inflammation & 40.00 & 29.27 \\
Bulging of mucosa & 37.78 & 7.31 \\
Pruritus & 8.89 & 68.29 \\
Jugal mucosal erythema & 6.67 & 2.44 \\
Eruption hematoma & 2.22 & - \\
Eruption cysts & 2.22 & 2.44 \\
Mouth ulcers & - & 12.20 \\
\hline
\end{tabular}

Table 2. Prevalence of systemic manifestations during dental eruption according to parents of GI and GII

\begin{tabular}{lll}
\hline Systemic Manifestations & GI (\%) & GII (\%) \\
Irritability & 84.44 & 70.73 \\
Fever & 62.22 & 53.66 \\
Disturbed sleep & 53.33 & 43.90 \\
Diarrhea & 42.22 & 53.66 \\
Increased intake of liquids & 20.00 & 21.95 \\
Vomiting & 6.67 & 7.31 \\
Nasal discharge & 4.44 & 12.20 \\
\hline
\end{tabular}


Table 3. Practices adopted by parents of GI to manage teething disturbances.

\begin{tabular}{ll}
\hline Parental Conduct & $\%$ \\
Consultation with doctor & 20.00 \\
Consultation with dentist & 15.56 \\
Use of a systemic anti-inflammatory & 4.44 \\
Application of topical anesthetic & 4.44 \\
Application of topical analgesic + rubber teether & 2.22 \\
Do nothing/ did not answer & $53.34 \%$ \\
\hline
\end{tabular}

Table 4. Practices adopted by parents of GII to manage teething problems.

\begin{tabular}{ll}
\hline Parental Conduct & $\%$ \\
Application of topical anesthetic & 17.07 \\
Use of a rubber teether & 14.63 \\
Application of topical anesthetic + rubber teether & 12.20 \\
Consultation with a pediatrician & 4.88 \\
Use of topical anesthetic and systemic analgesic & 4.88 \\
Consultation of a pediatric dentist and a doctor & 4.88 \\
Handling objects or solid food to the child (carrots) & 4.88 \\
Use of systemic analgesics & 2.44 \\
Use of gauze and water for cleaning & 2.44 \\
Do nothing/ did not answer & $31.7 \%$ \\
\hline
\end{tabular}

\section{Discussion}

The dental eruption is a normal physiological process, which can be modified by individual and environmental factors ${ }^{11}$ and has been the subject of studies and interest to pediatric dentists, pediatricians and general practitioners who deal with child patient ${ }^{12}$.

In this study, sample selection was made by convenience and also by age group of children, since eruption of primary teeth extends from the sixth to the thirtieth month child life. Although children above thirtieth month were included, it is justified because they still present primary teeth. It should be noted that this was a limitation in this study because mothers could not remember all events that had occurred during dental eruption of their children. However, considering the high percentages obtained, it must not had affected the results. A retrospective study based on the analysis of data collected from 450 medical records of children aged 6-60 months in order to analyze systemic and/or local manifestations related to teething showed that $80.9 \%$ of parents noted some alteration ${ }^{4}$.

For children with disabilities, the youngest and the oldest age were higher than the control group. It should be emphasized that the normal evolution of dentition depends on the physiological balance of whole body, being affected by factors of general nature, such as systemic or infectious diseases, genetic syndromes and endocrine alterations ${ }^{13}$. In children with Down syndrome, delayed tooth eruption, in part from delayed tooth formation, may be one of the first features noted and can occur in primary and permanent dentitions ${ }^{14}$.
According to the results, it was evident that all parents interviewed have noted the occurrence of systemic and/or local manifestations during tooth eruption and related it to the process. In a survey of Australian parents showed that a high percentage of parents believed that teething causes many systemic symptoms ${ }^{10}$. Another study conducted in Israel showed that $76.4 \%, 83.3 \%$ and $55.5 \%$ of parents, nurses and physicians, respectively, believed that tooth eruption was associated with infant morbidity ${ }^{15}$.

The results of this study were similar to those obtained by other authors who showed that most parents noticed some changes in child during the eruption of primary teeth ${ }^{5,10,16-24}$. In addition, more than one local and/or systemic manifestation were observed and related to the process of eruption.

According to parents of both groups, edema around the tooth was the most observed local manifestation ( $84.44 \%$ and $78.05 \%$ for GI and GII, respectively). Related to systemic manifestations, irritability and fever were the most frequent in both groups (Table 2). This result agrees with some studies that showed that the symptoms presented during the eruption of deciduous teeth couldn't be solely attributed to this process ${ }^{11,24}$. Moreover, they are mild and transient and do not undermine the general state of health of the child in the long term ${ }^{25}$. Other causes should be investigated by health professionals to provide favorable conditions for normal growth and development of children.

The perception of pediatric dentists and pediatricians about the relation between general and local manifestations with teething shows many differences. According to these professionals, the local manifestations were more related to the process than systemic manifestations ${ }^{17,26}$. They also prescribed various drugs for teething problems ${ }^{20}$.

Parents of GII adopted more and different practices to manage teething disturbances than those of GI. For GII, applying a topical anesthetic (17.07\%) and use a rubber teether $(14.63 \%)$ were the most common practices. For GI, parents would rather take their children to visit a doctor $(20.0 \%)$ or a dentist $(15.56 \%)$. Owais et al. ${ }^{18}$ observed that a high percentage of parents used systemic analgesics or applied topical analgesics in guns to relieve the symptoms associated with teething. In this study, a low percentage of parents used topical anesthetics, probably because the children have been assisted by an early oral health program in which parents receive instructions about these conditions. A cross-sectional study conducted with 1,500 parents treated at Maternity and Child Care Centers, showed that $76.1 \%$ used systemic analgesics and $65.6 \%$ rubbed the gingival tissues with topical analgesics to relieve the symptoms. The authors concluded that parents should be better educated about the teething process and the proper management of teething disturbances by the dental health care providers ${ }^{18}$.

According to results, all parents interviewed agreed that several local or systemic manifestations occurred during primary dental eruption and different practices were adopted to alleviate teething disturbances. 


\section{References}

1. Hulland SA, Lucas OJ, Wake MA, Hesketh KD. Eruption of the primary dentition in human infants: a prospective descriptive study. Pediat Dent. 2000; 22: 415-21.

2. Mota-Costa R, Medeiros-Júnior A, Aciolly-Júnior H, Araújo-Souza GC, Clara-Costa IC. Mothers' perception of dental eruption syndrome and its clinical manifestation during childhood. Rev Salud Publica. 2010; 12: 82-92.

3. Rezende CFM, Kuhn, E. Perception of mothers and pediatricians from Ponta Grossa/PR about alterations occurred in infants during the eruption of the primary dentition. Pesq Bras Odontoped Clin Integr. 2010; 10: 163-7.

4. Ferreira FV, Machado MVS, Ardenghi TM, Praetzel, JR. Systemic and/ or localized manifestations associated with primary tooth eruption: a retrospective study. Pesq Bras Odontoped Clin Integr. 2009; 9: 235-9.

5. Peretz B, Ram D, Hermida L, Otero MM. Systemic manifestations during eruption of primary teeth in infants. J Dent Child. 2003; 70: 70-3.

6. Jones M. Teething in children and the alleviation of symptoms. J Fam Health Care. 2002; 12: 12-3.

7. Silva FWGP, Santos BM, Stuani AS, Mellara TS, Queiroz AM. Dental eruption: symptomatology and treatment. Pediatria. 2008; 30: 243-8.

8. Noor-Mohammed R, Basha S. Teething disturbances: prevalence of objective manifestations in children under age 4 months to 36 months. Med Oral Patol Oral Cir Bucal. 2012; 17: 491-4.

9. Feldens CA, Faraco IM, Otoni AB, Feldens EG, Vitolo MR. Teething symptoms in the first year of life and associated factors: a cohort study. $J$ Clin Pediatr Dent. 2010; 34: 201-6.

10. Wake M, Heskeyh K, Allen MA. Parent beliefs about infant teething: a survey of Australian parents. J Paediatr Child Health. 1999; 35: 446-9.

11. Diniz MB, Bolini PDA, Gaspar AMM. Local and systemic symptoms related to deciduous tooth eruption. Rev Paul Pediatr. 2006; 24: 71-7.

12. Pinheiro GA, Casado LEM, Assunção VA. Tooth eruption - physiological or pathological phenomenon? Odontol Mod. 1993; 20: 28-33.

13. Suri L, Gagari E, Vastardis H. Delayed tooth eruption: pathogenesis, diagnosis, and treatment: a literature review. Am J Orthod Dentofacial Orthop. 2004; 126: 432-45.

14. Shore $S$, Lightfoot $T$, Ansell P. Oral disease in children with Down syndrome: causes and prevention. Community Pract. 2010; 83: 18-21.

15. Sarrell EM, Horev Z, Cohen Z, Cohen HA. Parents' and medical personnel's beliefs about infant teething. Patient Educ Couns. 2005; 57 : $122-5$.

16. Andrade DR, Silva C, Paiva SM. Local and general reactions occurred in children facing the process of eruption of deciduous teeth. RGO. 1999; 47 : 219-24.

17. Lovato M, Pithan SA. Perception of pediatrics, pediatric dentistry and parents about the clinical manifestations attributed to the eruption of deciduous teeth. Stomatos. 2004; 10: 15-20.

18. Owais Al, Zawaideh $F$, Bataineh $O$. Challenging parents' myths regarding their children's teething. Int J Dent Hyg. 2010; 8: 28-34.

19. Kiran K, Swati T, Kamala BK, Jaiswal D. Prevalence of systemic and local disturbances in infants during primary teeth eruption: a clinical study. Eur J Paediatr Dent. 2011; 12: 249-52.

20. Oziegbe EO, Esan TA, Adekoya-Sofowora CA, Folayan MO. A survey of teething beliefs and related practices among child healthcare workers in lle-Ife, Nigeria. Oral Health Prev Dent. 2011; 9: 107-13.

21. Adimorah GN, Ubesie AC, Chinawa JM. Mothers' beliefs about infant teething in Enugu,South-east Nigeria: a cross sectional study. BMC Research Notes. 2011; 4: 228.

22. Kakatkar G, Nagarajappa R, Bhat N, Prasad V, Sharda A, Asawa K. Parental beliefs about children's teething in Udaipur, India: a preliminary study. Braz Oral Res. 2012; 26: 151-7.

23. Ramos-Jorge J, Pordeus IA, Jorge MLR, Paiva SM. Prospective longitudinal study of signs and symptoms associated with primary tooth eruption. Pediatrics. 2011; 128: 471-7.
24. 24 Vasques EFL, Vasques EFL, Carvalho MGF, Oliveira PT, GranvilleGarcia AF, Costa EMMB. Clinical manifestations attributed to the eruption of deciduous teeth - perception and attitude of parents. RFO-UPF. 2010; 15: 124-8.

25. Ginani F, Vasconcelos RG, Barboza CAG. Local and systemic symptoms associated to tooth eruption. Rev Bras Sci Saude. 2011; 15: 81-6.

26. Aragão AKR, Veloso DJ, Melo AUC. Pediatricians and pediatric dentists from João Pessoa opinions' about deciduous tooth eruption and infantile symptomatology. Com Cienc Saude. 2007; 18: 45-50. 